\title{
Review
}

\section{The pancreatic beta-cell as a fuel sensor: an electrophysiologist's viewpoint*}

\author{
P. R orsman \\ Department of Islet Cell Physiology, Novo Nordisk A/S, Copenhagen, Denmark
}

Summary The pancreatic beta cell serves as the fuel sensor of the entire body and controls, via secretion of the hypoglycaemic hormone insulin, the blood glucose concentrations within narrow limits by regulation of glucose uptake and release. During the last 30 years, a combination of biochemical and ultrastructural approaches has resulted in dramatic progress in the understanding of the processes by which glucose and other nutrients modulate the release of insulin. The beta cells have also been investigated using electrophysiological techniques and were thus found to be electrically excitable and to undergo complex changes in their membrane potential when exposed to glucose and other stimulators of secretion. The application of the patch-clamp technique to the pancreatic islet preparations has revolutionized the understanding of how bioelectrical processes participate in the fuel-sensing of the beta cell. An important achievement was the identification of an ATP-sensitive $\mathrm{K}^{+}$-channel as the resting and glucose-sensitive membrane conductance of the beta cell. This channel also constitutes the target of the hypoglycaemic sulphonylureas: a group of compounds which have been used successfully in the treatment of insulin-dependent diabetes mellitus for several decades. [Diabetologia (1997) 40: 487-495]

Keywords Ion channels, ATP, insulin, exocytosis, pancreas.
The central role of ions in the control of cellular excitability has been recognized for more than a century and dates back to the pioneering work of Ringer [1]. For a long time, electrical excitability was a property believed to be confined to a small group of highly sophisticated cells such as nerve and muscle cells in which the role and need of electrical signalling was obvious. However, during the 1960 s and 1970 s it became obvious that a number of endocrine cells share this capacity and that they utilize changes in their membrane potential to transduce changes in their

* The 31st Minkowski lecture given in the Austria Centre, Vienna, Austria, 4 September, 1996.

Corresponding author: Dr. P. Rorsman, Department of Islet Cell Physiology, Novo Nordisk A/S, Fruebjergvej 3, DK-2100 Copenhagen, Denmark

Abbreviations: K-ATP channel, ATP-sensitive potassium channel; PKA, protein kinase A. environment to acceleration of hormone secretion $[2,3]$.

\section{The pancreatic beta cell is electrically excitable}

In 1968 Dean and Matthews [3] provided the first evidence for glucose-stimulated electrical activity in the pancreatic beta cell. The salient features of this electrical activity are summarized in Figure 1. In the absence of glucose, or at substimulatory glucose concentrations $(<7-8 \mathrm{mmol} / \mathrm{l})$, the membrane potential of the beta cell is negative $(-60 \mathrm{mV})$. Following elevation of glucose to insulin-releasing concentrations, the beta cell depolarizes and once the cell becomes sufficiently depolarized (i.e. exceeds the "threshold potential"), electrical activity is generated. This electrical activity consists of slow oscillations in membrane potential between a depolarized plateau, on which action potentials are superimposed (active 


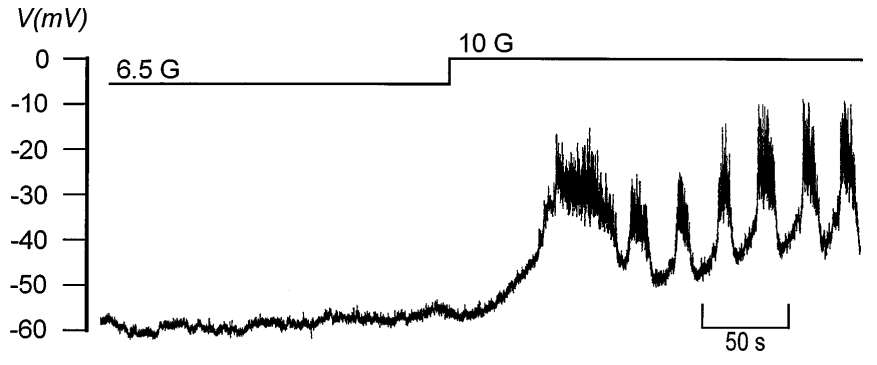

Fig. 1. The membrane potential (V) of a single beta cell within an intact pancreatic islet recorded in the presence of 6.5 and $10 \mathrm{mM}$ glucose as indicated by the staircase

phase), and repolarized electrically silent intervals. The beta cell responds to glucose in a graded fashion: the fraction active phase increases as the glucose concentration is raised until electrical activity becomes continuous at concentrations above $20 \mathrm{mmol} / \mathrm{l}$. The induction of electrical activity is a key event in the sequence of events that culminates in the release of insulin and it has been possible to demonstrate that the periods of electrical activity coincide with pulsatile insulin secretion [4]. More extensive accounts of the beta cell electrical activity have been published and interested readers are referred to these for a detailed description $[5,6]$.

ATP-sensitive $\mathrm{K}^{+}$-channels: the biophysical basis for the fuel-sensing of the beta cell

Recordings using intracellular electrodes impaled into the beta cell in intact pancreatic islets have been invaluable in determining the effects of insulin-releasing agents on the membrane potential and electrical activity of the beta cell (reviewed in [5]). However, because it was not possible to control the membrane potential of the preparation using this technique, the identity and characteristics of the ion channels underlying the electrical activity could not be determined. Such analyses had to await the application of the patch-clamp technique to pancreatic islet cells [7]. This technique, the features of which relevant to the study of pancreatic beta cells have been described at length elsewhere [6], permits the recording under voltage-clamp conditions (i.e. the membrane potential is kept constant irrespective of any activation of membrane currents) of both the minute single-channel and the whole-cell currents; the latter reflecting the summed activity of all the ion channels in the entire plasma membrane. The introduction of the patch-clamp technique revolutionized electrophysiology and in just a few years transformed it from an "art", practised in only a few laboratories, into a standard technique of cell physiology. Using the various recording modes of the patchclamp technique it became possible to demonstrate that the glucose-sensitive resting conductance of the beta cell is due to the activity of $\mathrm{K}^{+}$-channels which are inhibited by intracellular ATP (the K-ATP channel) [7-11]. The regulation of the K-ATP channel is extremely complex but there is now agreement that changes in the cytoplasmic ATP/ADP-ratio represents an important determinant of channel activity $[11,12]$. In parallel with the work on the K-ATP channel, the voltage-dependent membrane currents participating in the generation of the beta cell action potential were characterized. In mouse beta cells, which represent the "classic" preparation for electrophysiological experiments, the depolarizing phase of the action potential is attributable to the activation of voltage-gated $\mathrm{Ca}^{2+}$-channels which are sensitive to dihydropyridines such as nifedipine (L-type $\mathrm{Ca}^{2+}$-channels) $[13,14]$. The repolarization of the action potential principally results from the opening of voltage-dependent $\mathrm{K}^{+}$-channel with a time course of activation which is delayed relative that of the $\mathrm{Ca}^{2+}$-channels (hence delayed rectifying $\mathrm{K}^{+}$-current) $[13,15,16]$.

The K -A TP channel: a "target" of the hypoglycaemic sulphonylureas

Following the identification of the K-ATP channel as the glucose-sensitive membrane conductance of the beta cell it was proposed that this channel also represents the target of the hypoglycaemic sulphonylureas, compounds which have been used in the treatment of non-insulin-dependent diabetes for several decades. With the aid of the patch-clamp technique it was possible to show that this was indeed the case and that therapeutic concentrations of the sulphonylureas produce a concentration-dependent inhibition of the K-ATP channel [17-19]. The exact nature of the interactions between the sulphonylureas and the KATP channel could not be resolved in the first patch-clamp experiments, but the observation that they remained inhibitory in isolated membrane patches enabled the conclusion that their effect is not secondary to interference with beta cell metabolism. Some of the sulphonylureas were found to be very potent inhibitors of the K-ATP channel. For example, glibenclamide was effective at nanomolar concentrations [19]. By using the sulphonylureas as ligands it was thereby possible to purify and eventually to clone the sulphonylurea receptor. Thanks to these efforts we now know that the K-ATP channel is a complex of a $145 \mathrm{kDa}$ sulphonylurea receptor (SUR; [20]) and an inward rectifier $\mathrm{K}^{+}$-channel protein (KIR6.2; [21, 22]). Hopefully this novel molecular information can be exploited in current and future endeavours to develop new and more tissue-selective antidiabetic compounds. In this context it is pertinent that K-ATP channels in different tissues 


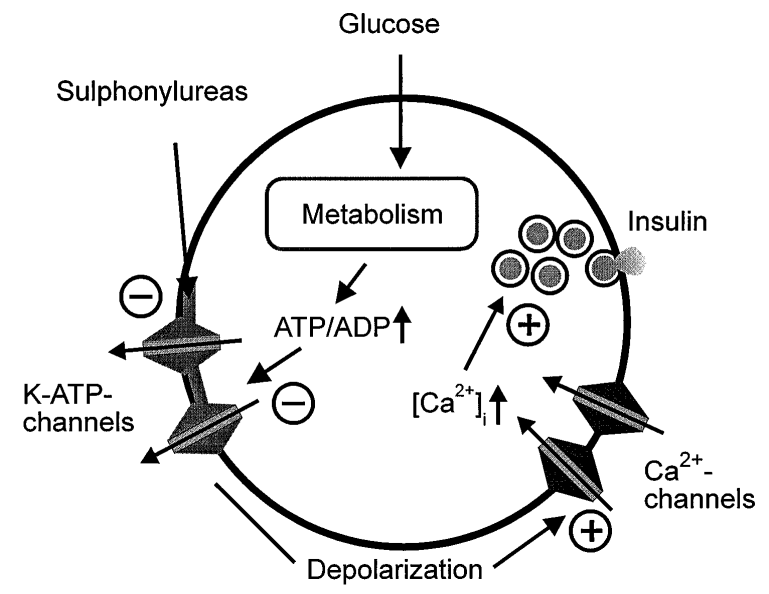

Fig. 2. Schematic model for the stimulus-secretion coupling of the pancreatic beta cell. Glucose produces, via its metabolism, an increased cytoplasmic ATP/ADP-ratio which inhibits the $\mathrm{K}$-ATP channels. This results in membrane depolarization and the opening of voltage-dependent $\mathrm{Ca}^{2+}$-channels, an increase in $\left[\mathrm{Ca}^{2+}\right]_{i}$ and the initiation of exocytosis of the insulin-containing secretory granules. Also indicated in the model is the site of action of the hypoglycaemic sulphonylureas which inhibit the K-ATP channels by a direct effect which is not dependent on glucose metabolism

have distinct molecular composition. For example, the K-ATP channels in cardiac and beta cells contain distinct isoforms of SUR (denoted SUR2 and SUR1, respectively) [23]. This accounts for the different pharmacological properties of cardiac and beta cell $\mathrm{K}-\mathrm{ATP}$ channels. It is not known which SUR is present in the K-ATP channels in smooth muscle cells (e.g. those in the blood vessels) but it is likely to represent yet another isoform of SUR as neither SUR1 nor SUR2 is expressed in smooth muscle preparations.

\section{A model for glucose-stimulated insulin secretion}

A simple model for the stimulus-secretion coupling of the pancreatic beta cell is shown in Figure 2. In the absence of glucose, the cytoplasmic ATP/ADP ratio is low and the K-ATP channels are active. Each beta cell is equipped with thousands of K-ATP channels and their summed activity effectively clamps the beta-cell membrane potential at the $\mathrm{K}^{+}$ equilibrium potential which (with the $\mathrm{K}^{+}$-gradients existing over the beta-cell membrane) is around $-70 \mathrm{mV}$. Ion channels other than the K-ATP channels are present, and perhaps active even in the absence of glucose, but they are too few to influence the membrane potential as long as the K-ATP channels remain active. When the beta cell is exposed to glucose, the associated acceleration of glucose metabolism leads to a rise in the cytoplasmic ATP/ADP-ratio and the K-ATP channels close. Once they are almost completely inhibited ( $>90 \%$ ), the remaining KATP conductance is unable to balance the depolarizing influence of (tonically active?) background conductance(s) and the beta cell depolarizes. When this depolarization is large enough, voltage-gated $\mathrm{Ca}^{2+}$ channels become activated in a feed-forward manner (i. e. the initial depolarization up to the threshold potential causes the opening of a few voltage-gated $\mathrm{Ca}^{2+}$-channels which in turn causes a bigger depolarization and the opening of additional $\mathrm{Ca}^{2+}$-channels with resultant further depolarization, etc), thus accounting for the upstroke of the beta-cell action potential. The associated $\mathrm{Ca}^{2+}$-influx causes a transient elevation of the cytoplasmic $\mathrm{Ca}^{2+}$-concentration $\left(\left[\mathrm{Ca}^{2+}\right]_{\mathrm{i}}\right)[24]$ which, via a series of poorly defined reactions, culminates in the exocytosis of the insulincontaining granules.

The unique feature of the pancreatic beta cell, essential for its ability to serve as the body's fuel sensor, is the presence of the K-ATP channels. As discussed above, the activity of these channels sets the membrane potential of the beta cell and thus determines its electrical and secretory activities. If the beta cell had not been equipped with K-ATP channels, it would have been tonically active and constantly releasing its insulin into the circulation regardless of the glucose concentration. Indeed, these are precisely the characteristics of beta-cells isolated from patients with persistent hyperinsulinaemic hypoglycaemia of infancy [25]. This rare hereditary disease is linked to mutations in SUR [26], which is part of the K-ATP channel complex (see above), and thus results in the formation of non-functional K-ATP channels. The fact that K-ATP channels play such an important role in the stimulus-secretion coupling of the beta cell does not exclude, however, that metabolic regulation of more distal processes also contributes to the overall fuel-sensing of the beta cell. For example, there is evidence suggesting that glucose metabolism may control both the functional state of the voltagegated $\mathrm{Ca}^{2+}$-channels [27] (thus determining the amount of $\mathrm{Ca}^{2+}$-entry and the extent of $\mathrm{Ca}^{2+}$-induced exocytosis) as well as the insulin secretory process itself [28]. The objective of beta-cell electrical activity is to generate the intracellular signal that initiates the exocytosis of the insulin-containing granules. In the remainder of this review I shall therefore discuss the control of exocytosis in the insulin-secreting beta cell and consider various modulatory mechanisms.

\section{Capacitance measurements of insulin secretion}

Elucidation of the fundamental properties of exocytosis requires a means to record secretion in single cells with high temporal (millisecond) resolution. Unfortunately, none of the traditional biochemical 
Capacitance measurements

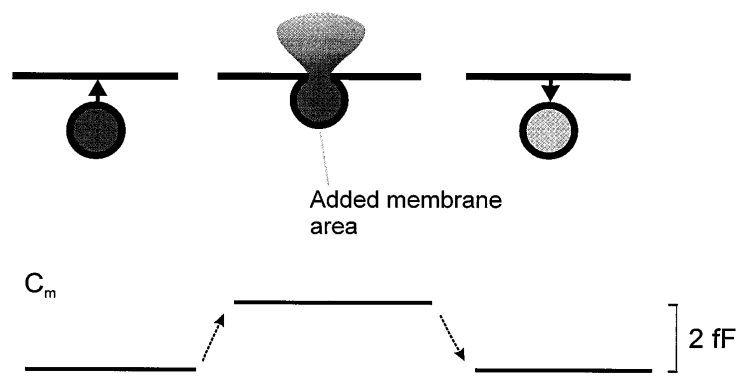

Fig. 3. Principle for capacitance measurements of exocytosis. The exocytosis of a secretory granule (left and centre) results in the incorporation of the granular membrane with the plasma membrane. The added membrane causes an increase in cell surface area which can be detected as an increase in cell capacitance $\left(\mathrm{C}_{\mathrm{m}}\right)$, an electrical parameter of the cell which is proportionally related to the surface area $\left(A ;\right.$ i.e. $\left.C_{m} \propto A\right)$. The specific membrane capacitance is $10 \mathrm{fF} / \mu^{2}$. The surface area of a secretory granule can be estimated as $0.2 \mu \mathrm{m}^{2}$ assuming spherical geometry and a granule diameter of $0.25 \mu \mathrm{m}$ [30]. The fusion of a single granule accordingly results in a capacitance increase of $2 \mathrm{fF}$. When a granule is subsequently retrieved by endocytosis, a corresponding decrease in cell capacitance can be recorded (right)

approaches for measuring insulin release have achieved this resolution. We have therefore been obliged to monitor changes in cell capacitance as an indicator of exocytosis. The membrane capacitance (C) is an electrical property of the cell which is proportionally related to the cell surface area. When the insulin-containing granules undergo exocytosis, their membranes are incorporated into the plasma membrane (Fig. 3). The resulting increase in cell surface area can be monitored as an increase in cell capacitance using electrophysiological techniques [29]. The major advantages of capacitance measurements over more traditional approaches to study secretion are: 1 ) the measurements can be carried out in single cells with millisecond resolution; 2) the experiments are carried out in a voltage-clamped preparation: i.e. any effects of a compound on membrane conductances and membrane potential will not influence the results; and 3) large proteins such as antibodies can be applied intracellularly by including them into the pipette solution which replaces the cytoplasm when utilizing the whole-cell recording mode of the patchclamp technique. The specific capacitance of biological membranes (including those of the plasma membrane and the secretory granules) is $\approx 10 \mathrm{fF} / \mu \mathrm{m}^{2}$. With a diameter of $250 \mathrm{~nm}$ [30], each beta-cell granule can be estimated to add $0.2 \mu \mathrm{m}^{2}$ of membrane area which corresponds to $2 \mathrm{fF}$ of capacitance. Capacitance increases with this unitary amplitude have been recorded [31] and may accordingly reflect single exocytotic events (i.e. the fusion of an individual granule with the plasma membrane). It must be kept in mind that recordings of cell capacitance do not involve measurements of insulin secretion as such but changes in a physical property of the cell which hopefully reflect exocytosis. To ascertain that this is indeed the case we have combined capacitance measurements with fluorimetric and/or electrochemical detection of insulin secretion [32]. So far we have encountered no discrepancies between the capacitance measurements and secretion detected by the alternative methods making it reasonable to conclude that an increase in cell capacitance can be equated to exocytosis. The conclusion is reinforced by the observations that insulin secretion and exocytosis as reported by the capacitance measurements exhibit the same $\mathrm{Ca}^{2+}$-dependence [32], are equally affected by cooling [33] and similarly modulated by hormones and neurotransmitters [34, 35]. Capacitance measurements finally offer the unique possibility of studying the retrieval of the secreted membranes by endocytosis. In this case, membrane retrieval results in a decreased membrane surface area and thus a reduction of the cell capacitance [36].

\section{Exocytosis in the beta cell is rapid}

Using capacitance measurements it was possible to demonstrate that the latency between the opening of the $\mathrm{Ca}^{2+}$-channels and the onset of exocytosis is less than $50 \mathrm{~ms}$. This is shorter than the time required for $\left[\mathrm{Ca}^{2+}\right]_{\mathrm{i}}$ to equilibrate within the beta cell which suggests that the $\mathrm{Ca}^{2+}$-channels, the secretory granules and the release sites are situated in the near vicinity of each other. During the first $50 \mathrm{~ms}$ the rate of capacitance increase approached $1 \mathrm{pF} / \mathrm{s}$. Using the conversion factor of $2 \mathrm{fF} /$ granule this can be converted to an exocytotic rate of 500 granules/s. Since a beta cell contains 13000 granules [30], this value corresponds to a release rate of $4 \%$ of the total granule number being released per second! Clearly, exocytosis can only continue at this high rate for a very limited period and during protracted stimulations exocytosis proceeds at much slower average rates. This decline in the exocytotic rate reflects the gradual depletion of the pool of granules which is immediately available for release ("the readily releasable pool"). Once this pool has been depleted other processes, such as the refilling of the readily releasable pool (see below), become rate-limiting to exocytosis.

It should be made clear that the short latency $(<50 \mathrm{~ms})$ observed in the capacitance measurements does not imply that the release process (including the dissolution of the $\mathrm{Zn}^{2+}$-insulin crystal) is completed within this time span: the latency is simply a reflection of the time required for the granular membrane to fuse with the plasma membrane and thus be detected by the capacitance measurements. Even so the above considerations illustrate the high speed and capacity of the exocytotic machinery in the beta cell. 
M odulation of $\mathrm{Ca}^{2+}$-induced exocytosis

Exocytosis in the beta cell is clearly $\mathrm{Ca}^{2+}$-dependent but $\mathrm{Ca}^{2+}$ should perhaps be regarded as an initiator rather than a determinant of exocytosis. This is suggested by the observation that the amplitude of the exocytotic responses depends to a greater extent on the activity of protein kinases and phosphatases than the actual $\left[\mathrm{Ca}^{2+}\right]_{\mathrm{i}}$. For example, agents which increase cytoplasmic cyclic AMP levels, such as glucagon and glucagon-like peptide-1, potentiate glucosestimulated insulin secretion by a protein kinase A (PKA)-dependent mechanism almost 10 -fold without much affecting $\mathrm{Ca}^{2+}$-influx or $\left[\mathrm{Ca}^{2+}\right][34$, unpublished data]. In the case of glucagon-like peptide-1 (GLP-1), no stimulation of exocytosis was observed in the absence of glucose suggesting that ATP derived by glucose metabolism is required for the PKA-dependent phosphorylation. Our capacitance measurements indicate that this stimulation principally results from PKA accelerating granule mobilization from the reserve pool into the readily releasable pool thus increasing the size of the latter over fivefold. When exocytosis is subsequently initiated by elevation of $\left[\mathrm{Ca}^{2+}\right]_{i}$, a greater number of granules are available for release. We have previously postulated that cAMP acts by "sensitizing" the secretory machinery [34]. However, the fact that the relationship between $\left[\mathrm{Ca}^{2+}\right]_{\mathrm{i}}$ and exocytosis remains the same in the absence and presence of cAMP is hard to reconcile with such a concept and an increased size of the readily releasable pool may produce effects on exocytosis which at first glance are difficult to distinguish from a sensitizing mechanism.

The molecular mechanism by which PKA accelerates granule mobilization remains obscure. In nerve endings, PKA is known to exert a similar action as in the beta cell by phosphorylation of the protein synapsin-1 which controls the interactions between the vesicles and the cytoskeleton. Synapsin-1 is not expressed in pancreatic beta cells but a synapsin-1-like protein, which may fulfill the function of synapsin-I, has recently been characterized in insulin-secreting cells [37].

$\mathrm{Ca}^{2+}$-induced exocytosis is also enhanced by agents which activate protein kinase $\mathrm{C}$, such as $\mathrm{ACh}$ and the phorbol ester $4-\beta$-phorbol- $12-\beta$-myristate13- $\alpha$-acetate (PMA) [35]. In general, conditions which promote protein phosphorylation lead to enhancement of secretion. Conversely one would expect that agents which produce the activation of protein phosphatases inhibit exocytosis. Indeed, this seems to be the mechanism by which the inhibitory hormones and neurotransmitters somatostatin, galanin and adrenaline suppress glucose-stimulated insulin secretion. The action of these compounds is mediated by activation of an inhibitory (pertussis toxinsensitive) G-protein and culminates in the activation of the protein phosphatase calcineurin [38].
$H$ ypoglycaemic sulphonylureas stimulate insulin secretion by interaction with exocytotic machinery

Perhaps the most surprising finding that has emanated from the capacitance measurements is that the sulphonylureas, in addition to closing the K-ATP channels, also stimulate insulin secretion by direct interaction with the exocytotic machinery [39] (but see [40] for conflicting data). Such an effect is not easily detected in ordinary assays of insulin secretion as the stimulation of secretion resulting from the closure of the K-ATP effectively obscures any contribution of a late mechanism. Using capacitance measurements it became possible to separate the two effects as the membrane potential was voltage-clamped and thus held constant irrespective of K-ATP channel activity. An effect of the sulphonylureas on exocytosis would also be consistent with the ultrastructural and biochemical evidence indicating that as much as $90 \%$ of the sulphonylurea-binding in the beta cell is intracellular and localized to the secretory granules [41, 42].

The observations that the sulphonylureas interfere with exocytosis, possibly by binding to granular sulphonylurea receptors, raises several interesting questions: 1) Is the granular sulphonylurea receptor the same as the $145 \mathrm{kDa}$ SUR which is part of the K-ATP channel? 2) Do the granular sulphonylurea receptors couple to ion channels in the granule membrane. Sulphonylurea-sensitive membrane currents have been demonstrated in pancreatic zymogen granules and have been proposed to control the fusion process [43]. It is attractive to speculate that the sulphonylureas modulate exocytosis in the beta cell by interference with similar conductances in the insulin-containing granules. In this context it is of interest that the $145 \mathrm{kDa}$ sulphonylurea receptor has been reported to promiscuously couple to $\mathrm{K}^{+}$-channel proteins other than KIR6.2 and it is therefore possible that it may also associate with other channel proteins [44]; 3) What is the physiological role of the granular sulphonylurea receptors and do they participate in "normal" $\mathrm{Ca}^{2+}$-induced exocytosis? The answers to these questions are clearly central to the understanding of how the sulphonylureas stimulate exocytosis in the beta cell. However the significance of these results may not be limited to the understanding of the control of insulin secretion. The sulphonylureas have been postulated to enhance glucose uptake in fat cells [45, 46]; an effect which seems as controversial [47] as the effect on exocytosis in the beta cell [40]. Glucose uptake in fat cells involves the insertion of the glucose transporters into the plasma membrane by exocytosis of their intracellular storage vesicles $[48,49]$. Since exocytosis in various cell types appears to involve the same molecular processes it is attractive to speculate that the mechanism we have described in the pancreatic beta cell is also operational in other cells (such as 
adipocytes) and accounts for some of the reported extrapancreatic actions of the sulphonylureas.

\section{M etabolic regulation of exocytosis}

In this review I emphasize the metabolic regulation of the beta cell. I have already described how ATP, via regulation of the K-ATP channels, controls the membrane potential and thereby $\mathrm{Ca}^{2+}$-influx and $\mathrm{Ca}^{2+}$-induced exocytosis. However, there is evidence suggesting that ATP also controls insulin secretion in a more direct way. Experiments on permeabilized insulin-secreting cells have indicated that withdrawal of ATP from the cytoplasm results in $90 \%$ inhibition of exocytosis [50]. Moreover, glucose exerts a strong stimulatory action (particularly at late times) in cells which are already maximally depolarized by high extracellular $\mathrm{K}^{+}$, i.e. under conditions where the sugar is unable to act via depolarization and elevation of $\left[\mathrm{Ca}^{2+}\right]_{\mathrm{i}}[28]$. Collectively these observations indicate that access to cytoplasmic ATP (or another glucose metabolite) is somehow rate-limiting to exocytosis. We have applied capacitance measurements in conjunction with photorelease of caged $\mathrm{Ca}^{2+}$ from its caged "precursor" $\mathrm{Ca}^{2+} / \mathrm{NP}-\mathrm{EGTA}$ to test this hypothesis. A representative experiment is shown in Figure 4. Here $\left[\mathrm{Ca}^{2+}\right]_{\mathrm{i}}$ was elevated in two different cells which were dialysed with an ATP-containing or an ATP-free solution. Whereas elevation of $\left[\mathrm{Ca}^{2+}\right]_{i}$ in the presence of ATP produced a biphasic stimulation of exocytosis (seen as rapid initial increase in cell capacitance followed by a sustained second slower phase), no change in cell capacitance was observed in the absence of ATP. If anything, the response in the latter cell consisted of a transient decrease in cell capacitance which may reflect endocytosis of granules that had been inserted in the plasma membrane during the period required for the wash-in of the $\mathrm{Ca}^{2+} /$ NP-EGTA complex and the concomitant wash-out of the endogenous ATP. $\mathrm{Ca}^{2+}$-induced exocytosis in the beta cell is clearly highly dependent on access to cytoplasmic ATP. In this respect the pancreatic beta cell differs from other neuroendocrine cells. In both chromaffin and pituitary cells, large exocytotic responses can be obtained long after complete wash-out of ATP [51]. As I shall try to explain below, this does not necessarily imply that the biochemical regulation of exocytosis in the beta cell differs from that in the other cell types in any fundamental way.

As alluded to above, both ultrastructural and functional studies have suggested that the granules in endocrine cells exist in pools of different "releasability" [52]. A small fraction of the total granule population is immediately available for release and accordingly designated as "the readily releasable pool". These granules are probably located just beneath the

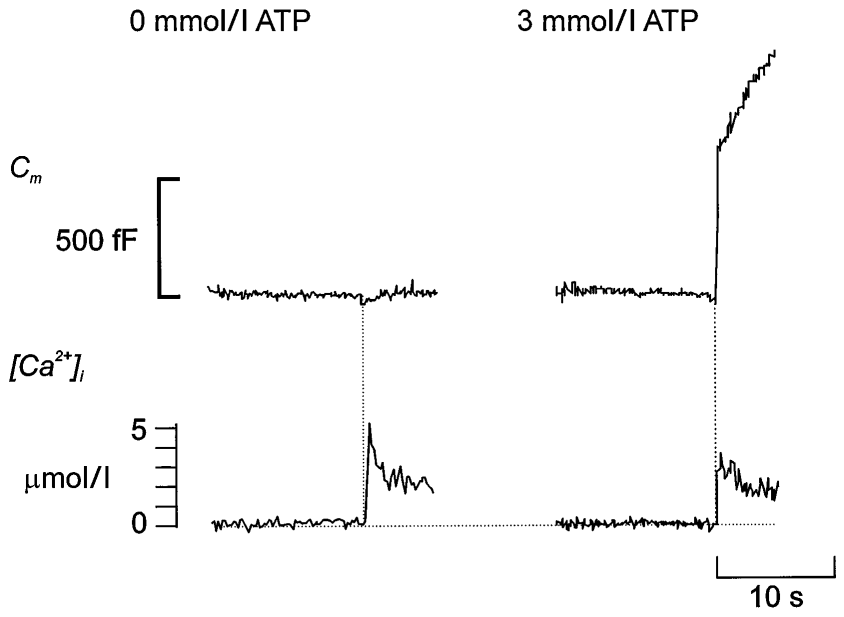

Fig. 4. Exocytosis is ATP-dependent. Exocytosis (monitored as an increase in cell capacitance; $\mathrm{C}_{\mathrm{m}}$ ) was elicited by photorelease of $\mathrm{Ca}^{2+}$ from its caged precursor $\mathrm{Ca}^{2+} / \mathrm{NP}-\mathrm{EGTA}$ which had been preloaded into the cell. Upon irradiation with ultraviolet light, the affinity of NP-EGTA for $\mathrm{Ca}^{2+}$ is dramatically reduced resulting in the "release" of $\mathrm{Ca}^{2+}$. Photolysis was effected as indicated by the dotted vertical lines in the presence (right) and absence of ATP (left). Note the failure of $\mathrm{Ca}^{2+}$ to elicit exocytosis in the absence of ATP. The capacitance increase in the presence of ATP $(\approx 1000 \mathrm{fF})$ corresponds to the release of 500 secretory granules

membrane and are the first to undergo exocytosis when $\left[\mathrm{Ca}^{2+}\right]_{i}$ is elevated. The vast majority of granules are not immediately available for release and presumably located further away from the plasma membrane. These granules need to be "mobilized" into the readily releasable pool before they can be released and are referred to as the "reserve pool". The "mobilization" of the granules may involve either their physical translocation within the cell, a chemical modification of the granules (such that the release probability is increased) or both.

According to current biochemical models of exocytosis, hydrolysis of ATP is required in the chemical modification of the granules which precedes exocytosis ("priming"). When $\left[\mathrm{Ca}^{2+}\right]_{\mathrm{i}}$ subsequently rises to exocytotic levels, the primed granules (and only those) can be released in a process which does not require any further consumption of ATP. However, the pool of primed/energized granules is of limited size and once these granules have been released the pool needs to be replenished in an ATP-dependent way by mobilization of granules from the reserve pool. A simple explanation to the apparent greater ATP-dependence of exocytosis in the beta cell than in the other neuroendocrine cells is therefore that the insulin-secreting cell contains fewer primed granules. In the pituitary cell, the size of this pool has been estimated both functionally and by electron microscopy. Both methods suggest that the primed pool comprises $\approx 4000$ granules. This is considerably higher than the corresponding number in the pancreatic beta 


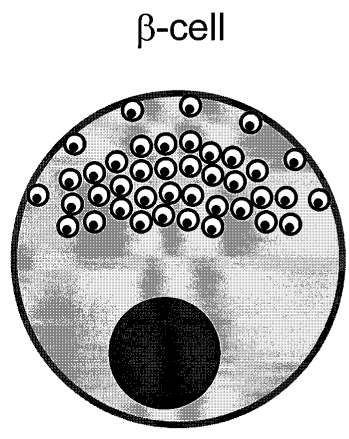

$<100$ energized granules
Pituitary melanotroph

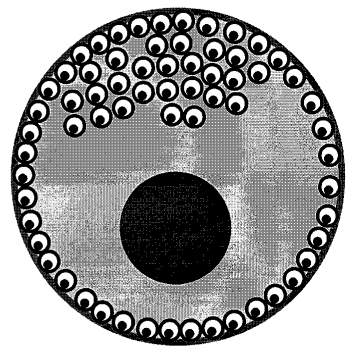

3000 energized granules

Fig. 5. Comparison of the number of primed granules in the beta cell and in a pituitary cell. The pituitary cell contains a much larger number pool of primed (energized) granules, which are located just beneath the plasma membrane and that can be rapidly released in a seemingly ATP-independent fashion when $\left[\mathrm{Ca}^{2+}\right]_{\mathrm{i}}$ is elevated, than the beta cell
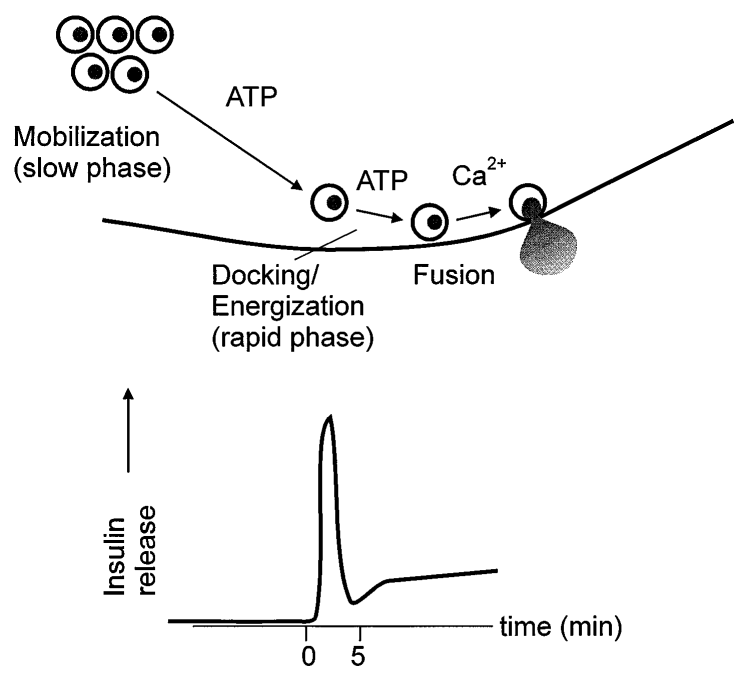

Fig. 6. Biphasic glucose-stimulated insulin secretion can be explained as the release of distinct pools of granules. The first phase of insulin secretion can be accounted for by the release of readily releasable (primed/docked) granules which are located immediately below the plasma membrane. The second slower phase results from the time- and ATP-dependent mobilization of granules situated further away from the plasma membrane

cell. Based on our capacitance measurements, we estimate that only $15-50$ granules (Fig. 5), or $0.1-0.3 \%$ of the total granule population ( $\approx 13000[30])$, exist in the "primed" state and are capable of being released in an ATP-independent fashion. Since the number of energized granules in the beta cell is only $\approx 1 \%$ of that in the pituitary cell, it is not surprising that insulin secretion exhibits a higher ATP dependence. It seems possible that this represents an important functional adaptation as keeping the number of energized granules low provides the beta cell with the means of rapidly adjusting its secretory capacity to the metabolic state.

Comparison with insulin secretion

A rapid elevation of $\left[\mathrm{Ca}^{2+}\right]_{i}$ produces a biphasic stimulation of exocytosis consisting of an initial rapid increase in cell capacitance followed by a second slower phase (Fig. 4). This biphasic response can be interpreted as the release of different pools of granules. Whereas the first rapid phase is likely to correspond to the release of granules situated immediately beneath the membrane (the readily releasable and/or primed pool), the second slower phase reflects the mobilization of the granules from the reserve pool. The biphasic increase in cell capacitance is clearly reminiscent of the biphasic nature of glucose-stimulated insulin secretion [53] and it is attractive to speculate that it can be explained in similar terms (Fig. 6). In fact, the size of the readily releasable pool which can be released in an ATP-independent fashion compares favourably with the number of granules that can be estimated to undergo exocytosis during the first phase of glucose-stimulated insulin secretion (L. Eliasson, P. Rorsman, unpublished data). Using photorelease of ATP from a caged precursor we believe it has been possible to estimate the time required for a granule to pass from the reserve pool into the readily releasable pool and to be released. We consistently observed a delay of $\approx 10 \mathrm{~s}$ between the application of ATP and the onset of secretion under experimental conditions that ensure that the primed/readily releasable pool was previously depleted. The long latency argues that the process of mobilization involves physical translocation, and not just chemical modification, of the granules.

\section{G lucose metabolism, A TP and diabetes}

In this review I have attempted to illustrate how glucose metabolism, via changes in the cytoplasmic ATP concentration, exerts its control of insulin secretion. The action of ATP is exerted at several levels. First, it controls the size of the readily releasable pool of granules by regulating the rate of granule mobilization/priming. Secondly, ATP generated by glucose metabolism determines the amplitude of $\mathrm{Ca}^{2+}$ evoked secretion via protein kinase A and C-dependent phosphorylation of exocytosis-regulating proteins. Thirdly, glucose metabolism modulates the activity of the voltage-dependent $\mathrm{Ca}^{2+}$-channels and thus $\mathrm{Ca}^{2+}$-entry and $\mathrm{Ca}^{2+}$-induced secretion. Finally, by controlling the activity of the ATP-sensitive $\mathrm{K}^{+}$channel, ATP regulates the membrane potential of the beta cell and thereby the electrical and secretory activities. Because ATP exerts so many regulatory functions it is not surprising that conditions which interfere with the ability of the beta cell to generate ATP have marked effects on its secretory capacity. For example, it has been reported that increased 
activity of ATP-consuming substrate cycles of glucose metabolism (e.g. glucose $\rightarrow$ glucose 6-phosphate $\rightarrow$ glucose; reactions catalysed by glucokinase and glucose 6-phosphatase, respectively) is an early sign of human non-insulin-dependent diabetes [54, 55]. Such a defect will not only interfere with the ability of glucose to depolarize the beta cell but also, as outlined above, reduce the refilling of the readily releasable pool thus possibly accounting for absence of a first phase of glucose-stimulated insulin secretion in these patients [56]. Finally, it deserves pointing out that currently available pharmacological principles for the treatment of non-insulin-dependent diabetes, such as the sulphonylureas, only rectify the inability of glucose to close the K-ATP channel but fail to correct the other ATP-dependent steps and these accordingly require alternative therapeutic approaches.

A cknowledgements. I thank the present and past members of my group (Dr. K. Bokvist, Dr. P. A. Smith, Dr. O. Larsson, Dr. C. Ämmälä, Dr. L. Eliasson, Dr. E. Renström, Dr. J. Gromada, Dr. L. Best and Dr. W.-G. Ding) for their hard work, loyalty and enthusiasm. During the last 10 years I have had a fruitful and productive collaboration with Professor F.M. Ashcroft (Oxford) and Professor P. O. Berggren (Stockholm). Finally I wish to express my gratitude to Dr. G. Trube for first introducing me to the patch-clamp technique. Supported in part by The Juvenile Diabetes Foundation, The Swedish Medical Research Council, The Nordic Insulin Foundation, The Swedish Diabetes Association and the Novo Nordisk A/S.

N ote added in proof. Recently Isomoto et al. (J Biol Chem 271: 24321-24324, 1996) describe an isoform of the cardiac sulphonylurea receptor (SUR2B). This isoform is present in smooth muscle cells and, when it is coexpressed with KIR6.2, forms K-ATP channels with the pharmacological properties of the smooth muscle type of the channel.

\section{References}

1. Ringer S (1883) A further contribution regarding the influence of the different constituents of blood on the contraction of the heart. J Physiol 4: 29-42

2. Dean PM, Matthews EK (1968) Electrical activity in pancreatic islet cells. Nature 219: 389-390

3. Taraskevich PS, Douglas WW (1977) Action potentials occur in cells of the normal anterior pituitary gland and are stimulated by the hypophysiotropic peptide thyrotropin releasing hormone. Proc Natl Acad Sci USA 74: 4064-4067

4. Barbosa RM, Silva AM, Tomé AR, Stamford JA, Santos RM, Rosario LM (1996) Real time electrochemical detection of 5-HT/insulin secretion from single pancreatic islets: effects of glucose and $\mathrm{K}^{+}$depolarization. Biochem Biophys Res Commun 228: 100-104

5. Henquin JC, Meissner HP (1984) Significance of ionic fluxes and changes in membrane potential for stimulus-secretion coupling in pancreatic B-cells. Experientia 40: 1043-1052

6. Ashcroft FM, Rorsman P (1989) Electrophysiology of the pancreatic $\beta$-cell. Prog Biophys Molec Biol 54: 87-143

7. Hamill OP, Marty A, Neher E, Sakmann B, Sigworth FJ (1981) Improved patch-clamp techniques for the recording from cells and cell-free membrane patches. Pflügers Arch 291: 85-100

8. Cook DL, Hales CN (1984) Intracellular ATP directly blocks $\mathrm{K}^{+}$-channels in pancreatic B-cells. Nature 312: 271-273

9. Ashcroft FM, Harrison DE, Ashcroft SJH (1984) Glucose induces closure of single potassium channels in isolated rat pancreatic $\beta$-cells. Nature 312: 446-448

10. Rorsman P, Trube G (1985) Glucose-dependent $\mathrm{K}^{+}$-channels in pancreatic $\beta$-cells are regulated by intracellular ATP. Pflügers Arch 405: 305-309

11. Misler S, Falke LC, Gillis K, McDaniel ML (1986) A metabolite-regulated potassium channel in rat pancreatic Bcells. Proc Natl Acad Sci USA 83: 7119-7123

12. Dunne MJ, Petersen OH (1986) Intracellular ADP activates $\mathrm{K}^{+}$-channels that are inhibited by ATP in an insulin-secreting cell line. FEBS Lett 208: 59-62

13. Rorsman P, Trube G (1986) Calcium and potassium currents in mouse pancreatic $\beta$-cells under voltage-clamp conditions. J Physiol 374: 531-550

14. Rorsman P, Ashcroft FM, Trube G (1988) Single Ca channel currents in mouse pancreatic B-cells. Pflügers Arch 412: 597-603

15. Smith PA, Bokvist K, Arkhammar P, Berggren PO, Rorsman P (1990) Delayed rectifying and calcium activated $\mathrm{K}^{+}$-channels and their significance for action potential repolarization in mouse pancreatic $\beta$-cells. J Gen Physiol 95: 1041-1059

16. Bokvist K, Rorsman P, Smith PA (1990) Effects of external tetraethylammonium and quinine on delayed rectifying $\mathrm{K}^{+}$-channels in mouse pancreatic $\beta$-cells. $\mathrm{J}$ Physiol 423: 311-325

17. Sturgess NC, Ashford MLJ, Cook DL, Hales CN (1985) The sulfonylurea receptor may be an ATP-sensitive potassium channel. Lancet II: 474-475

18. Trube G, Rorsman P, Ohno-Shosaku T (1986) Opposite effects of tolbutamide and diazoxide on the ATP-dependent $\mathrm{K}^{+}$-channel in mouse pancreatic $\beta$-cells. Pflügers Arch 407: 493-499

19. Zünkler BJ, Lenzen S, Männer K, Panten U, Trube G (1988) Concentration-dependent effects of tolbutamide, meglitinide, glipizide, glibenclamide and diazoxide on ATP-regulated $\mathrm{K}^{+}$-currents in pancreatic B-cells. Arch Pharmacol 337: 225-230

20. Aguilar-Bryan L, Nichols CG, Herrera-Sosa H, Nguy K, Bryan J, Nelson DA (1995) Cloning of the $\beta$-cell high-affinity sulfonylurea receptor: a regulator of insulin secretion. Science 268: 423-426

21. Inagaki N, Gonoi T, Clement JP IV et al. (1995) Reconstitution of $\mathrm{I}_{\mathrm{KATP}}$ : an inward rectifier subunit plus the sulfonylurea receptor. Science 270: 1166-1170

22. Sakura H, Ämmälä C, Smith PA, Gribble FM, Ashcroft FM (1996) Cloning and the functional expression of the cDNA encoding a novel ATP-sensitive potassium channel subunit expressed in pancreatic $\beta$-cells, brain, heart and skeletal muscle. FEBS Lett 377: 338-344

23. Nichols CG, Shyng SL, Nestorowicz A et al. (1996) Adenosine diphosphate as an intracellular regulator of insulin secretion. Science 272: 1785-1787

24. Rorsman P, Ämmälä C, Berggren PO, Bokvist K, Larsson O (1992) Cytoplasmic calcium transients due to single action potentials and voltage-clamp depolarizations in mouse pancreatic B-cells. EMBO J 11: 2877-2884

25. Kane C, Shepherd RM, Squires PE et al. (1996) Loss of functional $\mathrm{K}_{\mathrm{ATP}}$ channels in pancreatic $\beta$-cells causes persistent hyperinsulinemic hypoglycemia of infancy. Nature Med 2: 1344-1347 
26. Thomas PM, Cote GJ, Wohlik N et al. (1995) Mutations of the sulfonylurea receptor gene in familial persistent hyperinsulinemic hypoglycemia of infancy. Science 268: 426-429

27. Smith PA, Rorsman P, Ashcroft FM (1989) Modulation of dihydropyridine-sensitive $\mathrm{Ca}^{2+}$-channels by glucose metabolism in mouse pancreatic B-cells. Nature 342: 550-553

28. Detimary P, Gilon P, Nenquin M, Henquin JC (1994) Two sites of glucose control of insulin release with distinct dependence on the energy state in pancreatic B-cells. Biochem J 297: 455-461

29. Neher E, Marty A (1982) Discrete changes of cell membrane capacitance observed under conditions of enhanced secretion in bovine chromaffin cells. Proc Natl Acad Sci USA 79: 6712-6716

30. Dean PM (1973) Ultrastructural morphometry of the pancreatic beta-cell. Diabetologia 9: 115-119

31. Ämmälä C, Eliasson L, Bokvist K, Larsson O, Ashcroft FM, Rorsman P (1993) Exocytosis elicited by action potentials and voltage-clamp calcium currents in individual mouse pancreatic B-cells. J Physiol 472: 665-688

32. Bokvist K, Eliasson L, Ämmälä C, Renström E, Rorsman P (1995) Co-localization of L-type $\mathrm{Ca}^{2+}$-channels and insulin-containing granules and its significance for the initiation of exocytosis in mouse pancreatic B-cells. EMBO J 14: 5057

33. Renström E, Eliasson L, Bokvist K, Rorsman P (1996) Cooling inhibits exocytosis in single mouse B-cells by suppression of granule mobilization. J Physiol 494: 41-52

34. Ämmälä C, Ashcroft FM, Rorsman P (1993) $\mathrm{Ca}^{2+}$-independent potentiation of insulin release by cyclic AMP in pancreatic $\beta$-cells. Nature 363: 556-558

35. Ämmälä C, Eliasson L, Bokvist K et al. (1994) Activation of protein kinases and inhibition of protein phosphatases play a central role in the regulation of exocytosis in insulin-secreting mouse pancreatic B-cells. Proc Natl Acad Sci USA 91: 4343-4347

36. Eliasson L, Proks L, Ämmälä C et al. (1996) Endocytosis of secretory granules in pancreatic $\beta$-cells evoked by transient elevation of cytosolic calcium. J Physiol 493: 755-767

37. Matsumoto K, Fukunaga K, Miyazaki J, Schichiri M, Miyamoto E (1995) $\mathrm{Ca}^{2+} /$ calmodulin-dependent protein kinase II and synapsin 1-like protein in mouse insulinoma MIN-6 cells. Endocrinology 136: 3784-3793

38. Renström E, Ding WG, Bokvist K, Rorsman P (1996) Neurotransmitter-induced inhibition of exocytosis in insulin-secreting $\beta$-cells by activation of calcineurin. Neuron 17: 513522

39. Eliasson L, Renström E, Ämmälä C et al. (1996) PKC-dependent stimulation of exocytosis by sulfonylureas in pancreatic $\beta$ cells. Science 271: 813-815

40. Garciabarrado MJ, Jonas JC, Gilon P, Henquin JC (1996) Sulfonylureas do not increase insulin secretion by a mechanism other than a rise in cytoplasmic $\mathrm{Ca}^{2+}$ in pancreatic B-cells. Eur J Pharmacol 298: 279-286

41. Carpentier JL, Sawano F, Ravazzola M, Malaisse WJ (1986) Internalization of ${ }^{3} \mathrm{H}$-glibenclamide in pancreatic islet cells. Diabetologia 29: 259-26
42. Ozanne SE, Guest PC, Hutton JC, Hales CN (1995) Intracellular localization and molecular heterogeneity of the sulphonylurea receptor in insulin-secreting cells. Diabetologia 38: 277-282

43. Thévenod F, Chathadi KV, Jiang B, Hopfer U (1992) ATPsensitive $\mathrm{K}^{+}$conductance in pancreatic zymogen granules: block by glyburide and activation by diazoxide. J Membr Biol 129: 253-256

44. Ämmälä C, Moorhouse A, Gribble F et al. (1996) Promiscuous coupling between the sulphonylurea receptor and inwardly rectifying potassium channels. Nature 379: 545-548

45. Tsiani E, Ramlal T, Leiter LA, Klip A, Fantus IG (1995) Stimulation of glucose uptake and increased plasma membrane content of glucose transporters in L6 skeletal muscle cells by the sulfonylureas gliclazide and glyburide. Endocrinology 136: 2505-2512

46. Müller G, Wied S (1993) The sulfonylurea drug, glimepiride, stimulates glucose transport, glucose transporter translocation, and dephosphorylation in insulin-resistant rat adipocytes in vitro. Diabetes 42: 1852-1867

47. Panten U, Schwanstecher M, Schwanstecher C (1992) Pancreatic and extrapancreatic sulfonylurea receptors. Horm Metabol Res 24: 549-554

48. Simpson IA, Cushman SW (1986) Hormonal regulation of mammalian glucose transport. Ann Rev Biochem 55: 1055-1089

49. Lienhard GE (1983) Regulation of cellular membrane transport by the exocytotic insertion and endocytotic retrieval of transporters. Trends Biochem Sci 8: 125-127

50. Regazzi R, Wollheim CB, Lang J et al. (1995) Vamp-2 and cellubrevin are expressed in pancreatic $\beta$-cells and are essential for $\mathrm{Ca}^{2+}$ but not for GTP $\gamma \mathrm{S}$ induced insulin secretion. EMBO J 14: 2723-2730

51. Parsons TD, Coorssen JR, Horstmann H, Almers W (1995) Docked granules, the exocytotic burst and the need for ATP hydrolysis in endocrine cells. Neuron 15: 1085-1096

52. Neher E, Zucker RS (1993) Multiple calcium dependent processes related to secretion in bovine chromaffin cells. Neuron 10: 21-30

53. Grodsky GM (1994) An update on implications of phasic insulin secretion. In: Pickup J, Williams G (eds) Textbook of diabetes. Blackwell Scientific Publications, Oxford, Vol. 1, pp. 421-430

54. Efendic S, Wajngot A, Vranic M (1985) Increased activity of the glucose cycle in the liver: early characteristic of type 2 diabetes. Proc Natl Acad Sci USA 82: 2965-2969

55. Khan A, Östenson CG, Efendic S (1994) Glucose cycling in pancreatic islets. In: Flatt P, Lenzen S (eds) Frontiers of insulin secretion and pancreatic B-cell research. Smith-Gordon, London pp. 103-111

56. Ramirez LC, Raskin P (1991) Pancreatic abnormalities in non-insulin-dependent diabetes mellitus. In: Pickup J, Williams G (eds) Textbook of diabetes. Blackwell Scientific Publications, Oxford, Vol. 1, pp. 198-204 